Revista Tecné, Episteme y Didaxis: TED. Año 2014, Número Extraordinario. ISSN Impreso: 0121-3814, ISSN web: 2323-0126

Memorias, Sexto Congreso Internacional sobre Formación de Profesores de Ciencias. 08 al 10 de octubre de 2014, Bogotá

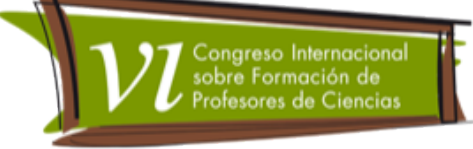

\title{
Observando el mundo con ojos de científicos
}

Espinosa Érica' ${ }^{1}$, Mesa Diana², Parra Sandra³, Ramírez Fernando4, Pedraza, Yamile5

Categoría: 2. Trabajo de investigación (en proceso)

\section{Resumen}

"La escuela primaria y secundaria es una etapa única para enseñar a mirar el mundo con ojos científicos: los estudiantes tienen la curiosidad, el asombro a flor de piel y el deseo de explorar el bien despierto" (Furman, 2008). Razón por la cual es fundamental contribuir en la búsqueda del desarrollo de un pensamiento científico en los estudiantes de esta edad escolar, a partir de la consolidación de escenarios alternativos al aula de clase tradicional donde se fomente el desarrollo de habilidades propias de las ciencias naturales.

A partir de esta necesidad surge la iniciativa de desarrollar un curso ciencia fuera de clase "Observando el mundo con ojos de científicos" como estrategia de aprendizaje que promueva la comprensión de la naturaleza y el trabajo científico, propiciando espacios de observación, reflexión y explicación sobre los fenómenos naturales que ocurren diariamente a nuestro alrededor. Para materializar estas acciones de pensamiento, la estrategia va encaminada a resolver ¿̇Qué habilidades científicas se potencializan en niños y niñas al desarrollar el curso Ciencia fuera del aula "observando el mundo con ojos de científicos"?

\section{Palabras clave}

Ciencias naturales, habilidades científicas, indagación, experimentación.

\footnotetext{
1 Licenciada en Ciencias Naturales y Educación Ambiental. Especialista en Gestión Ambiental. Universidad Pedagógica y Tecnológica de Colombia -UPTC-. Correo: edem1325@gmail.com 2 Licenciada en Ciencias Naturales y Educación Ambiental. Universidad Pedagógica y Tecnológica de Colombia -UPTC-. Correo: dianamesauptc@gmail.com 3 Licenciada en Ciencias Naturales y Educación Ambiental. Universidad Pedagógica y Tecnológica de Colombia -UPTC-. Correo: samipabo30@hotmail.com ${ }^{4}$ Licenciado en Ciencias Naturales y Educación Ambiental. Estudiante de Maestría en Educación. Universidad Pedagógica y Tecnológica de Colombia -UPTC-. Correo: josefercho@hotmail.com

${ }^{5}$ Magister en Educación Universidad de los Andes. Universidad Pedagógica y Tecnológica de Colombia -UPTC-. COORDINADORA DEL Correo: yamile.pedraza@uptc.edu.co
} 
Revista Tecné, Episteme y Didaxis: TED. Año 2014, Número Extraordinario. ISSN Impreso: 0121-3814, ISSN web: 2323-0126

Memorias, Sexto Congreso Internacional sobre Formación de Profesores de Ciencias. 08 al 10 de octubre de 2014, Bogotá

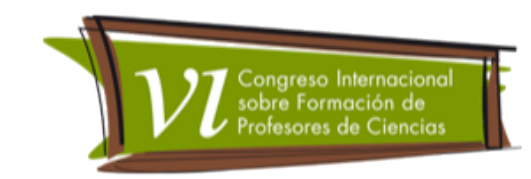

\section{Objetivos}

\section{$>$ Objetivo General}

Desarrollar habilidades científicas en los estudiantes que promuevan la comprensión de la naturaleza y el trabajo científico.

\section{$>$ Objetivos específicos}

- Identificar las habilidades científicas de los estudiantes a partir del análisis de fenómenos y contextos reales.

- Caracterizar las acciones pedagógicas-didácticas que aportaron elementos esenciales en la consolidación y desarrollo de habilidades científicas en los estudiantes.

- Evaluar los aportes del curso fuera de aula "observando el mundo con ojos de científicos" la enseñanza de las ciencias naturales.

\section{Marco teórico}

\section{$>$ Didáctica de las ciencias naturales.}

La didáctica de las ciencias naturales como disciplina científica, tiene sus inicios desde la epistemología evolucionista de Toulmin (1972) en términos de una empresa racional.

El modelo científico en la didáctica de las ciencias experimentales, sería aquel que se centrara en las interacciones entre las concepciones del profesor de ciencias y las ideas alternativas de los estudiantes mediadas por la transposición didáctica que el docente ha elaborado, para ser de una teoría o modelo científico objeto de trabajo en el aula y por las estrategias de enseñanza que se derivan de tal transposición.

Figura 1. Transposición.

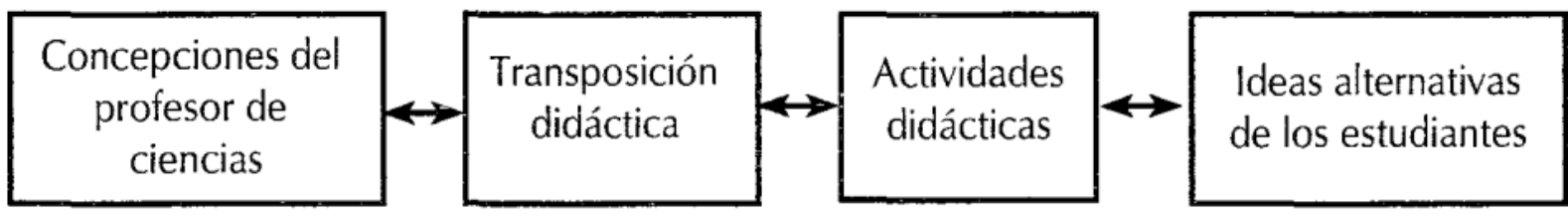

Fuente: Gallego Torres, A. (2006), Acerca de la didáctica de las ciencias de la naturaleza. Una disciplina conceptual y metodológicamente fundamentada. 
Revista Tecné, Episteme y Didaxis: TED. Año 2014, Número Extraordinario. ISSN Impreso: 0121-3814, ISSN web: 2323-0126

Memorias, Sexto Congreso Internacional sobre Formación de Profesores de Ciencias. 08 al 10 de octubre de 2014, Bogotá

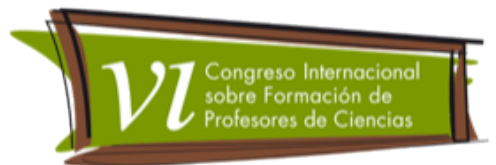

Las interacciones entre las concepciones del profesor de ciencias y las ideas alternativas de los estudiantes deben producir transformación, en relación con las estructuras conceptuales y metodológicas de la teoría o modelo científico didactizado, y en las concepciones del profesor, particularmente en cuanto a la didáctica y la pedagogía de la ciencia que hace objeto de trabajo en el aula. Las ideas alternativas de los estudiantes han de hacerse emerger como parte de las estrategias de enseñanza, y ser examinadas desde la estructura conceptual de la teoría o modelo científico que mediante la transposición didáctica se ha hecho objeto de trabajo en el aula.

\section{$>$ Enfoque por indagación}

La indagación es un proceso que se da en el pensamiento humano desde las primeras etapas de su desarrollo. El niño pequeño que tantea tratando de averiguar a dónde fue a parar la pelota, está haciendo inferencias mediante la indagación. También la indagación puede ser entendida como la habilidad para hacer preguntas, habilidad que tiene su origen en las necesidades del ser humano, el cual se convierte en un medio o instrumento para comprender y aprehender el objeto de estudio. John Dewey (1929), señalaba que la pregunta y la curiosidad, en cuanto actitud exploratoria, es la que da origen al pensamiento, decía, que en el niño la curiosidad es como un instinto natural y que en su crecimiento y participación en las relaciones sociales, éste se vale del lenguaje interrogativo, de las preguntas, para continuar explorando, por medio de los adultos, el mundo.

Connelly y otros (1977) conciben la indagación a tres niveles, en el primer nivel la relacionan con los procesos lógicos que se usan en el desarrollo y verificación del conocimiento. En un segundo nivel la conciben como una forma o modo de aprendizaje. Finalmente, la ven como una metodología de instrucción. Estos dos últimos significados, de acuerdo con su posición, son los de mayor aplicabilidad para el trabajo en el aula, porque consideran a la indagación como modo de aprendizaje y metodología de instrucción que hace énfasis en las ideas de los alumnos como los sujetos que resuelven o solucionan un problema o situación en los estudio, es decir, aquellos donde se formulan hipótesis, construyen conceptos o recogen datos y que además, pretenden ir más allá de la simple búsqueda de información de su objeto de estudio, plantean el tema de cómo indagan y exploran las pautas y procesos de razonamiento científico. Su énfasis esta en desarrollar patrones de autonomía en los alumnos y las alumnas respecto al 
Revista Tecné, Episteme y Didaxis: TED. Año 2014, Número Extraordinario. ISSN Impreso: 0121-3814, ISSN web: 2323-0126

Memorias, Sexto Congreso Internacional sobre Formación de Profesores de Ciencias. 08 al 10 de octubre de 2014, Bogotá

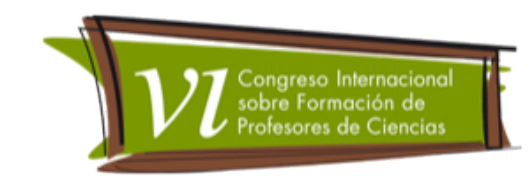

conocimiento científico y en cuanto a la capacidad intelectual de informarse por sí mismo. Camacho, H; Casilla, D; Finol de Franco, M. (2008).

\section{Metodología}

La metodología a implementar está estructurada en 3 grandes fases:

\section{Revisión y producción}

Durante esta fase, los investigadores realizaran una revisión bibliográfica exhaustiva sobre las metodologías de enseñanza y aprendizaje de los docentes y estudiantes alrededor de las ciencias naturales. Posteriormente a esta revisión se seleccionara el enfoque por el cual se dará desarrollo a las actividades de la investigación.

Las temáticas serán diseñadas teniendo en cuenta la siguiente estructura: exploración de conceptos previos, introducción de conceptos, actividad de aplicación, actividad de síntesis y comunicación, evaluación (Pedraza, 2011).

- Exploración de conceptos previos: los participantes se sitúan en la temática del objeto de estudio y formulan sus propios puntos de vista a través del desarrollo de actividades de indagación como: lluvia de ideas, cuestionarios, diagramas, observación, dialogo y análisis de situaciones (fenómenos) del contexto.

- Introducción de conceptos: se orienta al desarrollo de actividades que potencien la construcción o reconstrucción de nuevos aprendizajes de los participantes, por medio de actividades como: generación de predicciones, contrastes, esquematización y estructuración coherente de las diferentes formas de resolver los cuestionamientos planteados.

- Actividades de aplicación: busca confrontar las experiencias adquiridas con nuevas situaciones, a través del desarrollo de actividades como: observación y análisis del contexto, estudios de caso, experimentos, salidas de campo y prácticas de laboratorio.

- Síntesis y comunicación: se orienta al desarrollo de actividades que fomenten el intercambio de los nuevos aprendizajes entre los participantes, por medio de actividades como: el dialogo, debate, socialización de hallazgos, formulación de preguntas frente a cada temática y sintetizar importancia de la investigación científica en sus diferentes ramas.

- Evaluación: busca valorar y estimar el nivel de conceptualización científica a partir de los diferentes ejes temáticos y del curso en general por parte de los 
Revista Tecné, Episteme y Didaxis: TED. Año 2014, Número Extraordinario. ISSN Impreso: 0121-3814, ISSN web: 2323-0126

Memorias, Sexto Congreso Internacional sobre Formación de Profesores de Ciencias. 08 al 10 de octubre de 2014, Bogotá

participantes, a través de actividades como: realimentación constante de los investigadores, indagación oral y escrita y explicación de sucesos de la vida diaria.

\section{Implementación}

Durante esta fase se llevara a cabo el desarrollo del curso vacacional "observando el mundo con ojos de científicos", donde se implementaran las secuencias didácticas elaboradas anteriormente. Cada secuencia didáctica cuenta con la metodología propuesta por Pedraza (2011) y su evaluación será a partir de las respuestas y opiniones de los estudiantes.

\section{Evaluación}

En esta fase y una vez terminada la sistematización, la información se procederá a analizar y caracterizar en categorías de tipo inductivo, para lo cual se diseñara una matriz de evaluación cuyo es identificar y encasillar las habilidades científicas desarrolladas por los estudiantes.

Una vez terminada la etapa anterior, se procederá a consolidar una cultura científica en la población estudiantil a partir de la creación de clubes de ciencia, los cuales tendrán como característica esencial los resultados obtenidos por la fase y etapa anterior.

\section{Instrumentos}

- Cuestionarios

- Narrativas

- Entrevistas semi estructuradas

- Formatos evaluativos

- Análisis del discurso

\section{Resultados}

Esta investigación se encuentra en su fase de revisión y producción. Hasta la fecha no se tienen resultados en ninguna de sus fases. En caso de que la ponencia sea aceptada para la fecha del Congreso ya se podrá informar sobre lo que suceda en cada una de las fases del proyecto. Sin embargo haremos mención de algunos resultados que se esperan alcanzar con el desarrollo del curso vacacional "Observando el mundo con ojos de científicos". 
Revista Tecné, Episteme y Didaxis: TED. Año 2014, Número Extraordinario. ISSN Impreso: 0121-3814, ISSN web: 2323-0126

Memorias, Sexto Congreso Internacional sobre Formación de Profesores de Ciencias. 08 al 10 de octubre de 2014, Bogotá

- Se espera que desarrollado el curso los participantes estimulen la curiosidad y la fascinación por la ciencia.

- Puedan dar respuestas de carácter científico a las cosas (fenómenos) que pasan en su contexto y extrapolarlo a otras realidades del mundo.

\section{Conclusiones}

La enseñanza por indagación es una estrategia que promueve la comprensión de la naturaleza y el trabajo científico, proporciona espacios de observación, reflexión y explicación sobre los fenómenos naturales que ocurren diariamente a nuestro alrededor a partir de contextos reales.

Las temáticas a abordar en el desarrollo del curso promueven en los participantes el interés por el aprovechamiento de su tiempo libre en la conformación de redes y grupos (clubes) de ciencia que fortalezcan los procesos de comprensión de la ciencia en la ciudad de Tunja - Boyacá.

\section{Referencias bibliográficas}

Camacho, H; Casilla, D; Finol de Franco, M. (2008)La indagación: una estrategia innovadora para el aprendizaje de procesos de investigación Laurus, Vol. 14, Núm. 26, enero-abril, 2008, págs. 284-306 Universidad Pedagógica Experimental Libertador Venezuela.

Connelly, F; Finegold, M; Clipsham J; Wahlstrom, M (1977). Scientific Enquiry and the Teaching of Science. The Ontario Institute for Studies in Education

Dewey, J. (1929). The quest for certainty. Editorial. Putma, New York.

Furman, Melina (2008). Ciencias Naturales en la Escuela Primaria: Colocando las Piedras Fundamentales del Pensamiento Científico. IV Foro Latinoamericano de Educación.

Gallego Torres, A. (2006). Acerca de las didácticas de las ciencias de la naturaleza: una disciplina conceptual y metodológicamente fundamentada. Bogotá: Cooperativa Editorial Magisterio.

MEN. (2004). Estándares Básicos de Competencias en Ciencias Naturales y Ciencias Sociales. Ministerio de Educación Nacional de Colombia. 